Observer, is the poor mite called Cordelia). Yet, rightly or not, the public thinks he is talking through his own stetson, and their reason should give grim pleasure to academics who have felt despised and neglected for the last 11 years, because it is the most elementary research point. Mr Gummer wants us to believe that an absence of evidence is evidence for a negative, but everyone else in the country can see that to be false.

Dr Creutzfeld too might have been sceptical. The case he described in 1920 had also been dismissed at first as hysteria.

\title{
Reviews
}

Models of Clinical Management. By S. Disken, M. Dixon, S. Halpern and G. Shocket. London: Institute of Health Services Management. 1990. Pp 25. £5.95.

The drive to get doctors into management is propelled by the imperative to control overspending in the acute hospitals service. The aim is to ensure that those who spend most of the money should, through taking on responsibility for the planning and management of resources, become accountable for the improved use of those resources. That is possibly why the preface to this booklet is by the Director of Finance of the NHS Management Executive rather than a manager or doctor.

The mechanisms and management structures created to serve this end in 13 acute hospitals are reviewed here and three models emerge as potentially workable. All the models involve an extraordinary amount of fudging of lines of accountability between the clinicians in management, i.e. the clinical director and the unit general manager on the one hand and the clinical director and his consultant colleagues on the other-the latter relationship being a cross between a Member of Parliament for the Constituency of Surgery or Medicine or Psychiatry, say, and chief executive supremo John Harvey Jones style of Surgery or Medicine plc. It is pretty amazing then that up and down the country not only does clinical management seem to be working well in most hospitals which have adopted one of these models, but with government encouragement it will soon be a rarity for an acute hospital to be without clinical directors.

Lewisham and North Southwark health authority launched doctors into management in 1984 in all three Units, two acute hospital units, Guy's and Lewisham, and the Priority Care Unit. I have experienced life for two years as a clinical director and then witnessed the positive and negative impacts as UGM and DGM. The positive aspects are that doctors and managers really do begin to understand each other better and doctors begin to feel more involved in management decisions. Finances have been better controlled by devolving budgets to directorate control and the efficient use of drugs, path labs and X-ray has undoubtedly improved. From the doctors' and managers' point of view it has been a great success.

It has been less of a success from the nurses' point of view, who in the first years felt under-valued and disenfranchised from their traditional roles. Nurses largely determine and control the standards of patient care and to weaken their influence is both foolish and dangerous. It has taken all three units some time to understand the absolute necessity to provide strong clinical nursing leadership and a proper role for the senior nurse in a directorate. Similarly, other professional groups, such as the therapists, have been sidelined. In an era when good medicine involves a multidisciplinary approach to ward team work, the marginalising of other professional groups is unfortunate and a retrograde step in improving the culture in traditional clinical firms. The management of Guy's in particular is now dominated by the medical profession in a way which seems curiously old fashioned and inward looking. It takes a very skilled general manager and lateral thinking clinicians to ensure that all disciplines are involved in the management structure in a relevant and influential way. These problems are touched on by the authors but only the nursing issues are addressed adequately. 
Mental health services do not lend themselves well to medical management unless the doctor appointed can distance him or herself from the consultant role, involve other professions in the executive team and loosen his/her ties with the home hospital. Furthermore, management information on caseload activity, especially community work, is often rudimentary; the use of resources is crudely divided between professional groups. There is as yet no appropriate resource management information system geared to the needs of a community mental health catchment area service. In spite of these difficulties, and the dangers inherent in the system, it is probably one of the most effective ways of ensuring consultant commitment to service developments in mental health and controlling the budget in a clinically sensitive way.

If you are thinking of 'having a go' as a clinical director, or even if you just want to know what it might involve, this booklet will give you the framework - it won't, unfortunately, tell you how to do it.

Professor of Psychogeriatrics Elaine MURPHY United Medical \& Dental Schools. Guy's Hospital

London SE1 9RT

\section{Assuring Quality in Mental Health Services: The Quartz System. \\ By P. Clifford, R. Leiper, A. Lavender and S. Pilling. RDP (134/138 Borough High Street, London SE1 1LB) in association with Free Association Books (26 Freegrove Road, London N7 9RQ). 1989. Pp 88. £6.95.}

On seeing the title of this book, there will be many an aged and not so aged consultant who will say to himself "I didn't get where I am today by worrying about quality", and pass quickly on. Indeed, many would sympathise with this as the word quality was never heard when it could be taken for granted that hospitals were reasonably pleasant places. Probably, the idle cockroach always has been, and always will be, a feature of hospital, but surely not tragic old men found dead in the out-patient toilets.

All branches of medicine, spurred on by the White Paper, have been looking into medical audit, and setting up committees arranging weekly meetings and searching for outcome measures. The words quality assurance come in and regularly someone asks if quality assurance is synonymous with clinical audit.
This book does give a definition of quality assurance, and explains that it is the process through which institutions think about themselves and their clients. The book does not, however, directly compare this with the definition of audit as introduced in the White Paper. Quality assurance appears to be about institutions, and audit about medical or clinical care. Nonetheless, the two are inextricably entwined in community services, as well as in more obvious in-patient settings.

The theoretical background to the system suggested was introduced by a wide review of the literature. Prominent are the writings of Raynes and Wolfensberger, the influential writers on services to the mentally handicapped on each side of the Atlantic. Another important influence is that of Charles Shaw, whose work with the King's Fund is familiar to everyone who has embarked on any form of audit.

Quartz is an acronym for quality assurance teams of professionals from different areas within a service. The system is based strongly on schedules covering various topics of review, such as external links, management practices and client services review. It does, in one part, fulfil the secret dream of every audit committee and attempts to audit management. In some ways, it is broader in its scope than most practices that come more nearly under audit, and in others more restricted as it is more tied to an institution. Quality assurance can be a restrictive "navel contemplating" exercise, in which members of institutions constantly think about themselves and their clients, but nothing comes out, despite all the hours spent. In this book, quality assurance takes on the essential ingredient of audit in that it forms a cycle, taking this idea and acknowledging it from Charles Shaw's cycle.

This is a well-written book with an important suggestion which has been tried out in practice. Institutions who take audit seriously would be advised to read it, particularly as it attempts to tackle the inter-disciplinary problems and the difficulties of measuring across a wide variety of settings.

Does it tell us how to do audit? No, it does not, nor does it take the onus away from us at all. Medical audit, examination of medical services by doctors themselves, with the aim of improving care of patients and of educating ourselves and our juniors, remains our responsibility and a priority.

Consultant in Child and Adolescent Psychiatry ANN GATH

Hilda Lewis House

The Bethlem Royal Hospital

Croydon CRO 8DR 